\title{
Reflexões e inquietações acerca do ensino de língua inglesa nos anos iniciais
}

\author{
Jeovana Karla de Oliveira DIAS \\ Universidade Estadual de Goiás (UEG) \\ Giuliana Castro BROSSI \\ Universidade Estadual de Goiás (UEG)
}

\begin{abstract}
Resumo
Este estudo de caso discute as reflexões de uma professora e sua experiência no ensino de língua inglesa (LI), visando mostrar como se configura o ensino de LI nos anos iniciais em uma escola pública municipal de uma cidade do interior de Goiás. A metodologia adotada pauta-se na abordagem qualitativa, com a participação de uma professora de LI, que norteia sua práxis por uma perspectiva crítica de ensino de línguas. Os dados foram coletados no segundo semestre de 2013 e no primeiro de 2014, tendo como instrumentos questionário, observação de aulas, análise de planejamentos anual e semanal, diários reflexivos e entrevista. A análise dos dados está ancorada em estudos sobre a formação de professores reflexivos (PIMENTA, 2005), a perspectiva crítica de ensino de línguas (PENNYCOOK, 1990; 2010; 2012; MENEZES DE SOUZA, 2011; PESSOA, 2014; BORELLI; PESSOA, 2011) e o ensino de língua estrangeira para crianças (ROCHA, 2012; TONELLI, 2013; PEREIRA, 2007). Os resultados revelam crenças, expectativas e inquietações de uma profissional engajada com o ensino de LI e comprova a importância da formação continuada de professores/as de língua estrangeira.

Palavras-chave: professor reflexivo; anos iniciais; ensino crítico de línguas.
\end{abstract}

\begin{abstract}
This case study focuses on the reflections of a teacher of English as a Second Language for children, with the objective of presenting how the idiom is being taught in a city's public school in the state of Goias. The study used a qualitative data collection and analysis, and the participant in the research was an English teacher who bases her praxis on critical language teaching. The data was collected from August 2013 to May 2014, through questionnaires, class observations, curriculum and class planning analyses, reflexive diaries and an interview. We grounded the data analysis in theories of reflexive teacher education (PIMENTA, 2005), second language teaching through a critical perspective (PENNYCOOK, 1990; 2010; 2012; MENEZES DE SOUZA, 2011; PESSOA, 2014; BORELLI; PESSOA, 2011) and English as a second language teaching for children (ROCHA, 2012; TONELLI, 2013; PEREIRA, 2007). The results show beliefs, expectations and concerns of a teacher engaged with English teaching, and they demonstrate the significance of second language teacher continued education.
\end{abstract}

Keywords: reflexive teacher; early years basic education; critical language teaching. 


\section{INTRODUÇÃO}

$\mathrm{O}$ presente estudo originou-se de um projeto de pesquisa intitulado " $\mathrm{O}$ planejamento de curso, as crenças e ações de professores de LI nos anos iniciais: educação ou sofrimento?", proposto em 2012, fruto de reflexões sobre a experiência com o ensino de Língua Inglesa (doravante LI) nos anos iniciais em Anápolis - GO, como professora do ensino fundamental. Recentemente concursada, fui ${ }^{1}$ convidada a ministrar as aulas de LI nos anos iniciais, em uma escola de tempo integral, para completar a carga horária. Apesar da experiência que tenho como professora de LI há mais de quinze anos, a realidade de uma escola de tempo integral sem infraestrutura para receber as crianças o dia todo foi devastadora. Além do sofrimento que percebia nas crianças por estarem em um ambiente inadequado em tempo integral, a LI era vista como 'tapa-buracos' no horário e os professores anteriores, que trabalhavam atividades de gramática, de vocabulário e escrita com crianças do $1^{\circ}$ ao $5^{\circ}$ ano, se encarregaram de tornar a LI a disciplina 'mais chata' da escola, de acordo com as crianças. Outro agravante é que a escola não dispunha de material didático básico, como som ou televisão, bem como não havia planejamento anual ou diretrizes a serem seguidas pelo professor. Enfim, um cenário de muitas dúvidas, onde fiquei apenas alguns meses devido a uma situação pessoal.

Ao mesmo tempo, tornei-me professora formadora no curso de Letras da Universidade Estadual de Goiás, em Inhumas, onde ministrava Estágio Supervisionado em Língua Inglesa I, tendo a oportunidade de conhecer outra experiência de ensino de LI no ensino fundamental, inclusive nos anos iniciais. A partir de então, iniciei o processo de investigação, com o auxílio de duas graduandas voluntárias, que foram a campo observar as aulas de duas professoras de LI nos anos iniciais, em Inhumas, enquanto eu faria o mesmo em Anápolis.

O projeto de pesquisa, inicialmente, seria um estudo de múltiplos contextos com o objetivo de conhecer a realidade do ensino de LI nos anos iniciais em escolas públicas de tempo integral, nas duas cidades. No entanto, em Inhumas o ensino de LI é integrado à matriz curricular dos anos iniciais, como parte diversificada, desde 2009 (Secretaria Municipal de Educação). Ainda em 2012, em Anápolis, a LI foi abolida dessa escola em tempo integral devido à falta de professores disponíveis para assumir a carga horária.

\footnotetext{
${ }^{1}$ A narração em $1^{\text {a }}$ pessoa do singular na introdução expressa a voz da pesquisadora e orientadora do estudo. No decorrer do artigo a narração é feita no plural por representar as vozes das duas pesquisadoras.
} 
Portanto, o foco do projeto foi o ensino de LI nos anos iniciais em Inhumas. Apesar de termos investigado duas professoras, esse trabalho se limita aos dados resultantes da observação de aulas, questionário e entrevista com Stephany ${ }^{2}$.

Este estudo visa mostrar como se configura o ensino de LI nos anos iniciais em uma escola pública municipal em Inhumas, Goiás, tendo como perguntas de pesquisa as seguintes questões: Como a professora ministra aulas de LI nos anos iniciais? O que a professora diz sobre o ensino de LI para crianças?

O estudo será apresentado em seções, sendo a primeira uma revisão de literatura da área fundamentada em estudos sobre: o ensino de LI para crianças (ROCHA, 2012), o ensino crítico de línguas e o professor reflexivo. Em seguida, discorremos sobre o aparato metodológico utilizado para a coleta e análise dos dados, apresentados na seção seguinte.

\section{REVISÃO DA LITERATURA}

Alguns teóricos, entre eles Rocha (2012), defendem que a LI deve ser incluída no currículo dos anos iniciais, com base no direito de acesso aos bens culturais garantidos pela LDB, uma vez que a sua ausência pode ser caracterizada como "excludente e potencializadora de desigualdades" (op. cit.). No entanto, a mesma autora alerta para o risco de se elevar, ainda mais, o seu papel a de 'língua hegemônica', favorecendo o imperialismo linguístico. Diante de tal impasse, a autora enfatiza a necessidade de que a cultura da LI não deve ser tratada como comum, monolítica e monolíngue, e sim como um ambiente de integração de uma pedagogia crítica, no qual as diferenças sejam vivenciadas como constituintes da existência humana, com propostas que, de acordo com Canagarajah (1999), corroborem o caráter fluido de construtos como língua/linguagem, identidade e cultura, promovendo uma compreensão da língua/linguagem na sociedade mais rica e fortalecida.

Para Maher (2007), a cultura estrangeira em processos educacionais de base intercultural e plurilíngue deve ser 'destotalizada', o que implica transcender estereótipos e visões monolíticas sobre cultura e linguagem, não só a língua do outro, mas também a nossa, pois de acordo com Moita Lopes (2005), a diferença está em nós mesmos. Assim, ao pressupor que é na tensão entre eu e o outro que nos constituímos

\footnotetext{
${ }^{2}$ Nome fictício escolhido por questões éticas de preservação da identidade da professora participante.
} 
como pessoa (BAKHTIN, 2003), no âmbito da cultura, é também a distância que nos move a compreender as diferenças e/ou características próprias de cada cultura. Para promover o contínuo questionamento das relações que produzem desigualdades e sofrimento humano, buscando romper com a tendência de se enxergar o diferente de forma unívoca e seguir padrões culturais modelares, torna-se essencial a construção do pensamento crítico e transformador por meio do ensino da LI nos anos iniciais.

O mundo infantil está repleto de valores e ideias preconcebidas, constituídas pelas relações dialógicas travadas com o outro, que nesse caso pode ser o colega de classe, o professor, familiares, pessoas da convivência comunitária, falantes de outras línguas que se conhecem por meio de relações virtuais. Dessa forma, a LI nos anos iniciais, assim como posteriormente, segundo Celani (2004, p. 121),

[...] contribui para o processo educacional como um todo, indo muito além da aquisição de um conjunto de habilidades linguísticas. Leva a uma nova percepção da natureza da linguagem, aumenta a compreensão de como a linguagem funciona e desenvolve maior consciência do funcionamento da própria língua materna.

Na medida em que a criança é capaz de refletir criticamente, se bem orientada, a aprendizagem de uma nova língua, no caso a LI, contribui de forma significativa para a compreensão de sua própria cultura, bem como a si própria, pelo contato com outras culturas e identidades. Com um olhar bakhtiniano, esse encontro dialógico, orientado para desenvolver a criatividade e a transformação irá fortalecer essa criança como pessoa, exercendo sua cidadania. Assim, ao considerarmos que a maioria dos alunos dos anos iniciais de escolas públicas pertence a classes menos favorecidas, a escola apresenta-se como o meio principal de contato com tais oportunidades de desenvolvimento.

Nessa perspectiva, o professor encarregado das aulas de LI nos anos iniciais assume um papel muito importante no letramento crítico dessas crianças, o que nos leva à necessidade de uma formação continuada adequada a essas exigências contemporâneas. Ao final dessa breve reflexão acerca da importância do ensino de LI nos anos iniciais na escola pública, propomos a questão que faz a intersecção entre o ensino de LI nos anos iniciais e a formação desse professor: como os professores de LI para crianças podem colaborar com a formação de cidadãos que reflitam sobre as desigualdades e comprometidos com a transformação social? (URZÊDA FREITAS, 2013) 
Inicialmente, é necessário assumir que os professores de LI se vejam como educadores, compromissados com seus alunos, com a sociedade e sua própria formação, reflexivos e críticos, "que têm como objetivo formar o cidadão brasileiro, antes de mais nada" (CELANI, 2008, p.37). A autora compreende que a prática reflexiva capacita os professores a lidar com a complexidade e a imprevisibilidade que caracterizam a escola e a sociedade, enquanto a prática crítica visa formar profissionais comprometidos com a cidadania. Para despertar esse 'compromisso com a cidadania' é necessário ir além da formação e treinamento profissional: deve-se investir na formação crítica (LEFFA, 2001) dos professores de LI, propondo uma reflexão sobre as razões que motivam determinada ação, preocupando-se com as teorias que permeiam o trabalho docente, além de cultivar uma prática problematizadora (PENNYCOOK, 2004), encorajando professores a desenvolver atitudes que lhes possibilitem 'esperar o inesperado' (PENNYCOOK, 2012), promovendo mudanças a partir de situações reais, que surgem espontaneamente na sala de aula.

Segundo Rocha (2012), o ensino de LI no Ensino Fundamental I (doravante EFI) público apresenta fatores que intensificam as desigualdades, tais como a má formação do professor de línguas e o caráter optativo da LI na Matriz Curricular do EFI. Contudo, é necessário desestabilizar tais visões de que o ensino de LI no EFI público não é possível, e compreender que a LI faz parte de "práticas sociais em que imperam a pluralidade de línguas e culturas e em que circulam simultaneamente uma multiplicidade de sentidos" (ROCHA, op. cit., p. 37). Portanto, o ensino/aprendizagem da LI terá uma fundamentação a partir do momento que haja uma proximidade do contexto sociocultural do aprendiz, que a aprendizagem não esteja diretamente ligada ao ensino do léxico e que haja problematizações de juízos de valor, visto que preconceitos e estereótipos podem estar sendo revelados e é necessário que se tornem objetos de reflexão, pois o conteúdo deve ter a função de um agente transformador. Desta forma, os profissionais que trabalham com o ensino de LI, segundo Cox e Assis-Peterson (2001, apud Rocha, 2012, p. 48), "não podem reduzi-lo a questões sociopsicológicas de motivação, a questões metodológicas, a questões linguísticas. A língua está imersa em lutas sociais, econômicas e políticas e isso não pode ser deixado de fora da cena da sala de aula", uma vez que é importante a/o desestabilização/conflito para o desenvolvimento e o crescimento do indivíduo. Em conformidade com a premissa 
bakhtiniana ${ }^{3}$, Rocha (op. cit.), no que diz respeito ao ensino de LI nos anos iniciais, argumenta

[e]m favor de que se problematizem, sob perspectivas protagonistas, (re)produções sociais e culturais que articulam discursos autoritários e de que se retome a ideia bakhtiniana de que tudo vive na fronteira de seu extremo oposto (ROCHA, op. cit., p. 67-68).

A problematização é um dos caminhos que contribuem para o desenvolvimento crítico do aprendiz, já que propagandas, canções, desenhos, dentre outros gêneros, trazem no encalço funcionamentos sociais, valores, concepções e orientações opressoras que, em um todo, torna-os inteligíveis e concretos, capazes de se moverem autoritariamente (BAKHTIN, 1998, apud, ROCHA, 2012), além de serem gêneros orais presentes no cotidiano do aprendiz.

Rocha (op. cit.), partindo dos pressupostos que tangem as teorias bakhtinianas, percebe as possibilidades de se tratar os alunos como sujeitos ocupantes de espaços discursivos particulares, pois cada qual possui sua singularidade. Portanto, a teoria bakhtiniana, além de permitir a travessia de fronteiras consideradas intransponíveis e a exploração de universos diferentes por meio das ações críticas, (re) criam novas culturas e identidades.

Ainda segundo a autora, a partir do momento no qual a criança é reconhecida como uma pessoa capaz de refletir criticamente, compreende-se que uma das mais importantes contribuições que podem gerar a aprendizagem de uma nova língua é levar o aprendiz a entender essa nova cultura. No entanto, para que haja este entendimento, é necessário o contato com essa nova cultura, o qual será proporcionado pelo educador.

Com o intuito de fundamentar a discussão que nos leva a responder a segunda pergunta desta pesquisa, de identificar as percepções e reflexões da participante sobre o ensino de LI nos anos iniciais, apresenta-se uma abordagem teórica sobre o professor reflexivo, que subsidia as reflexões apresentadas pela participante.

Conforme Pessoa e Borelli (2011), ao longo dos séculos, o processo de ensinoaprendizagem passou por diversas transformações. Nos séculos XIV e XV, os

\footnotetext{
${ }^{3} \mathrm{Na}$ premissa bakhtiniana, conforme Rocha (2012, p. 39), reconhece-se a natureza dialógica da linguagem e, também, "o ininterrupto movimento de contraposição e determinação entre o individual e o social" que permeia as relações humanas, formando o sujeito e a realidade. Para Bakhtin, o indivíduo, ao interagir dialogicamente com o passado, o presente e o futuro, conseguindo, desse modo, encontrar sua voz, orientando-a perante outras, combinando-a, contrapondo-a ou, ainda, diferenciando-a de outras vozes, se constitui e se transforma, ou seja, é necessária a troca de conhecimento e os questionamentos para que o indivíduo possa construir sua identidade.
} 
professores eram denominados mestres, ou seja, aqueles que transmitiam um determinado tipo de conhecimento, por exemplo, um gramático que ensinava apenas gramática. Contudo, na atualidade, o processo da ação docente configura-se em um modelo, denominado por Contreras (2002, apud Pessoa e Borelli, op. cit. p.09, grifo nosso) de "racionalidade técnica", isto é, com esse modelo o professor transmite o conhecimento baseado em um saber teórico e técnico o qual provém de uma pesquisa científica.

No caso de ensinar uma segunda língua ou língua estrangeira equivale, segundo Pessoa e Borelli (op. cit.),

\begin{abstract}
e ainda o faz em muitos contextos, ao emprego de um método de ensino. Este obviamente não se limita a técnicas, mas normalmente resulta de discussões teóricas pertencentes a um dado contexto histórico. Em geral, apresenta objetivos, concepções de ensino, língua, linguagem e aprendiz, bem como crenças sobre a natureza de ensino aprendizagem de línguas (PESSOA; BORELLI op. cit. p. 10).
\end{abstract}

Contudo, é necessário que o contexto social seja levado em consideração durante a aplicação do método de ensino para abarcar as necessidades dos aprendizes, além de envolvê-los para que não se sintam excluídos.

Ainda segundo as autoras, a tarefa de ensinar a LE deve levar em consideração os fatores macrossociais, nos quais se analisa a contribuição e a importância da LE na sociedade; os fatores microssociais, que se resumem ao processo de aquisição da LE dentro da sala de aula e a interação aluno/professor; e por fim, os fatores curriculares, tais como os objetivos, os métodos e a avalição.

\begin{abstract}
Assim, a proposta defendida atualmente pela área de formação de professores de língua estrangeira e pela linguística aplicada crítica, [...] busca enfrentar o conflito social sobre a finalidade do ensino e as consequências da aprendizagem em sala de aula. Objetiva, em suma, desenvolver uma prática reflexiva crítica e criativa, não simplesmente reprodutora. Tal prática inspira os estudos [...], que concebem professores em formação universitária e continuada como atores cuja formação docente é fundamental por saberes que eles mobilizam e por significados que eles mesmos produzem. Esses saberes que orientam essa ação precisam ser desenvolvidos e valorizados para que possam promover mudanças mais significativas no processo educacional, gerando resultados positivos na aprendizagem de todos os alunos [...] (PESSOA; BORELLI, 2011, p. 12-13).
\end{abstract}

A formação reflexiva promove a ressignificação do papel do educador quando este passa a questionar sua função técnica de aplicador de teoria (Pessoa e Borelli, op. cit.), pois refletir criticamente denota a busca da compreensão dos fatores, os quais abrangem os acontecimentos da sala de aula e os que interferem na educação, que 
intervêm nas práticas dos participantes, os quais estão sendo pesquisados, sejam eles professores, alunos, dentre outros.

Tendo revisitado a literatura que embasa essa investigação, passamos a descrever o aparato metodológico utilizado em seu desenvolvimento.

\section{APARATO METODOLÓGICO}

De acordo com Larsen-Freeman \& Long (1991, apud Brossi, 2008, p. 61), a pesquisa qualitativa "caracteriza-se por decifrar atitudes através do comportamento humano, partindo do próprio indivíduo", portanto é fundamental que as investigações busquem a compreensão das ações da professora participante nos eventos em sala de aula, destacando seus valores, crenças, representações, opiniões e atitudes.

Conforme Almeida Filho (2005, apud Brossi, op. cit.), a perspectiva qualitativa de pesquisa trabalha com dados singulares, únicos, assim, aproxima-se da realidade, já que a observação é natural, e há utilização de métodos variados e subjetivos. Além de natural, a observação proporciona uma visão êmica ${ }^{4}$ dos dados, que buscam compreender e interpretar, com profundidade, o comportamento da participante envolvida no processo.

Esta pesquisa configura-se como um estudo de caso, que conforme Lüdke (1986), sempre será uma investigação delimitada, devendo esclarecer seus contornos definidos no desenrolar da mesma. O estudo de caso pode ser similar a outros, mas, ao mesmo tempo, é distinto, por apresentar interesses próprios e singulares.

Ainda segundo Lüdke (1986), estudo de caso caracteriza-se por visar à descoberta; por enfatizar a interpretação em um contexto; por buscar retratar a realidade de forma completa e profunda; por usar uma variedade de fontes de informação; por revelar experiência vicária e permitir generalizações naturalísticas; por procurar representar os diferentes e às vezes conflitantes pontos de vista presentes numa situação social; e por fim, os relatos deste estudo utilizam uma linguagem e uma forma mais acessível do que os outros relatórios de pesquisa. Além disso, a utilização de diversos

\footnotetext{
${ }^{4}$ Conforme Rosa e Orey (2012, p. 867) a abordagem êmica busca compreender "determinada cultura com base nos referencias delas próprias", em outras palavras, é a visão interna dos observados que estão olhando de dentro, em uma postura particular, única e analítica. Exemplificando, enquanto a abordagem ética relaciona-se à visão do eu em direção ao outro, na abordagem êmica, corresponde a visão do eu em direção ao nosso. É ver o mundo como o olhar do outro.
} 
tipos de instrumentos para a coleta de dados possibilita uma visão mais completa do fenômeno em investigação (OLIVEIRA, 2013).

Esta investigação realizou-se em uma escola municipal, localizada em um bairro com predominância de população de classe média/baixa e baixa, situada na cidade de Inhumas/Goiás. Atualmente, a escola funciona em dois turnos, sendo ambos a $1^{\mathrm{a}}$ fase do ensino fundamental. A comunidade escolar é formada por crianças com idade entre 4 a 13 anos. O espaço físico é relativamente pequeno, com sete salas de aula, sala de informática que dispõe de três computadores, e um pequeno pátio coberto, o qual é utilizado para eventos e recreação.

A pesquisa está centrada no ensino de LI no EFI nas turmas do primeiro ao quinto ano do turno matutino e vespertino, sob a orientação da professora Stephany, responsável didática e pedagogicamente pelas aulas de língua inglesa do $1^{\circ}$ ao $5^{\circ}$ ano da escola campo deste estudo.

Stephany é professora de Língua Estrangeira - inglês, tem 26 anos de idade, nascida em uma pequena cidade do interior do estado. É graduada em Letras (Português- Inglês) pela Universidade Estadual de Goiás (UEG), Mestre em Letras e Linguística pela Universidade Federal de Goiás (UFG) e doutoranda em Linguística Aplicada também pela UFG.

Durante a coleta dos dados, Stephany se mostrou uma professora reflexiva por pensar sobre as ações que executa no contexto escolar, confrontando teoria e prática ao efetivar sua prática docente, uma vez que, segundo Pimenta (2005),

[...] o saber docente não é formado apenas da prática, sendo também nutrido pelas teorias da educação. Dessa forma, a teoria tem importância fundamental na formação dos docentes, pois dota os sujeitos de variados pontos de vista para uma ação contextualizada, oferecendo perspectivas da análise para que os professores compreendam os contextos históricos, sociais, culturais, organizacionais e de si próprios como profissionais (PIMENTA, 2005, p. 24).

Além de reflexiva, tanto em suas ações na sala de aula, como durante a entrevista, que será abordada adiante, Stephany revelou algumas crenças que direcionam suas ações, pois, de acordo com Barcelos (1999), o aprendizado recebe influência dos meios sociais, os quais gerarão as crenças que serão manifestadas tanto pelos alunos quanto pelos professores, por carregarem os hábitos, os valores familiares e o papel cultural.

No processo de investigação deste estudo, através das observações das aulas, questionários escritos, entrevistas, notas de campo, narrativa e análise do plano de 
curso, buscamos explicitar as crenças que envolvem as metodologias da participante, os procedimentos didáticos utilizados em suas aulas, suas reflexões e percepções em relação ao ensino de LI nos anos iniciais.

No início do ano letivo de 2013, fizemos contato com a direção da unidade escolar e com a participante com o propósito de recebermos a autorização verbal de ambas. Então, após a autorização, iniciamos as investigações.

Iniciamos a observação das aulas no período de maio a setembro de 2013. A participante ministrava duas aulas por semana, portanto, totalizaram 14 aulas observadas com duração de 50 minutos cada. Essas observações possibilitaram identificar as metodologias empregadas pela participante em sala de aula e as crenças que as permeavam. Depois de algumas observações, solicitamos o Plano de Curso, e não tivemos objeção de Stephany, que se prontificou em nos dar acesso aos planos diários. Posteriormente, entregamos o questionário escrito e a proposta da narrativa, com o intuito de observar os princípios que regem o ato de ensinar da participante. Por fim, em março/2014, realizamos uma entrevista em áudio para finalizar a coleta dos dados. A entrevista foi o único instrumento que não foi aplicado no momento de realização das aulas por requerer tempo, então foi marcado um horário com a participante para efetivá-la.

Para dar mais veracidade ao estudo, foram utilizados vários instrumentos de coleta dos dados, pois segundo Johnson (1992) “a triangulação dos dados é a tentativa de chegar ao mesmo significado através de, pelo menos, três abordagens independentes e diferentes (JOHNSON, op. cit., p. 90)", isto é, analisar os dados da pesquisa a partir de vários registros - entrevista, observações das aulas, notas de campo, etc. - com a finalidade de alcançar resultados que sejam mais confiáveis, provenientes de diversas fontes.

O presente estudo de caso não investiga universos abstratos através de estatísticas generalizantes, mas um universo concreto, alcançado por intermédio do estudo particular, específico e detalhado da realidade de uma professora, sua metodologia, suas decisões a respeito do planejamento, suas reflexões e a maneira como as crenças influenciam essas decisões. Com esta finalidade, selecionamos, criteriosamente, os instrumentos que proporcionam confiabilidade ao estudo. A tabela 1, a seguir, apresenta os instrumentos para a coleta, seus objetivos e a frequência da aplicação. Em seguida, iniciamos a discussão e análise dos dados. 


\begin{tabular}{|c|c|c|}
\hline Instrumentos & Objetivos & Frequências \\
\hline $\begin{array}{l}\text { Observação das } \\
\text { aulas }\end{array}$ & $\begin{array}{l}\text { Inferir crenças da professora por meio } \\
\text { de suas práticas. }\end{array}$ & $\begin{array}{l}2 \text { aulas por semana, } \\
\text { totalizando } 14 \text { aulas. }\end{array}$ \\
\hline $\begin{array}{l}\text { Notas de campo } \\
\text { da pesquisadora }\end{array}$ & $\begin{array}{l}\begin{array}{l}\text { Descrever eventos } \\
\text { impressões na sala de } \\
\text { pesquisadora. }\end{array} \\
\text { e }\end{array}$ & $\begin{array}{l}\text { Um registro para cada } \\
\text { aula, no total de } 14 \\
\text { registros. }\end{array}$ \\
\hline Narrativa & $\begin{array}{l}\text { Inferir as crenças, as reflexões e as } \\
\text { metodologias da } r \text { professora } \\
\text { participante por meio das experiências } \\
\text { narradas. }\end{array}$ & $\begin{array}{l}\text { Uma narrativa escrita, } \\
\text { realizada após um mês } \\
\text { da coleta de dados. }\end{array}$ \\
\hline $\begin{array}{l}\text { Questionário } \\
\text { escrito }\end{array}$ & $\begin{array}{l}\text { Coletar dados pessoais e sobre a } \\
\text { formação acadêmica da professora, } \\
\text { bem como a respeito de sua } \\
\text { competência linguística; } \\
\text { Identificar conceitos de } \\
\text { ensino/aprendizagem, } \\
\text { métodos e abordagens utilizadas e } \\
\text { preferidas pela professora e pelos } \\
\text { alunos. }\end{array}$ & $\begin{array}{l}\text { Um questionário } \\
\text { elaborado pela } \\
\text { pesquisadora o qual } \\
\text { foi entregue assim que } \\
\text { autorizada a } \\
\text { observação das aulas. }\end{array}$ \\
\hline $\begin{array}{c}\text { Entrevista } \\
\text { semiestruturada }\end{array}$ & $\begin{array}{l}\text { Inferir as crenças e as metodologias da } \\
\text { professora sobre o planejamento do } \\
\text { curso, as reflexões e percepções acerca } \\
\text { do ensino de LI para crianças. }\end{array}$ & $\begin{array}{l}\text { Entrevista em áudio } \\
\text { com duração de } \\
\text { aproximadamente uma } \\
\text { hora. }\end{array}$ \\
\hline $\begin{array}{l}\text { Análise dos } \\
\text { documentos }\end{array}$ & $\begin{array}{l}\text { Analisar o planejamento de curso da } \\
\text { professora, buscando inferir, a partir } \\
\text { da concepção do documento, as } \\
\text { crenças e as reflexões da professora. }\end{array}$ & $\begin{array}{l}\text { Análise do } \\
\text { planejamento de curso } \\
\text { realizado no início do } \\
\text { ano letivo }\end{array}$ \\
\hline
\end{tabular}

Quadro 1: quadro de instrumentos da pesquisa

\section{DISCUSSÃO E ANÁLISE DOS DADOS}

De acordo com Tonelli (2013, p. 303), as crianças conseguem aprender sentadas isoladamente, entretanto é a partir das interações que gerará a comunicação. Assim, pelo fato da aquisição de uma LE ser um processo interativo, é necessário promover tais momentos para que elas possam "interagir em um contexto significativo e interessante".

Para adquirir uma nova língua, segundo Moon (2000 apud Tonelli, 2013 p. 303), não é necessário que uma criança vá a outro país, mas que o educador proporcione ao aprendiz as necessidades reais de uso desta nova língua. Portanto, a autora sugere que o 
educador prepare um ambiente atrativo, convidativo, "cheio de vida, com cartazes e figuras dispostas", criando um clima propício para a aprendizagem. Neste sentido, durante as observações notamos que Stephany apresenta tal característica.

$\mathrm{Na}$ parede estão pregadas gravuras que denominam ordem ou pedido/cumprimentos. Abaixo das gravuras estão as escritas.

[Trecho da nota de campo sobre a Aula 1]

[...]. Utilizou-se o mural no qual os alunos desenharam comida e decoração da festa de aniversário.

[Trecho da nota de campo sobre a Aula 7]

Logo em seguida ela pega quatro folhas e escreve os climas [...], ou seja, um dá continuidade ao que o outro está desenhando para que posteriormente seja fixado na parede.

[Trecho da nota de campo sobre a Aula 9]

Durante as observações, em relação ao uso de imagens para propiciar um ambiente atrativo, foi possível perceber que Stephany proporciona este ambiente ao utilizar imagens que os próprios alunos produzem durante suas aulas. As imagens são utilizadas com outras finalidades, como ocorreu na Aula 7, em que Stephany utilizou o mural que os alunos produziram com desenhos de decorações e comidas de festas de aniversário para exercitar o vocabulário.

Considerando os problemas que envolvem o ensino de LI no EFI público, Stephany busca facilitar a aprendizagem da LI, envolvendo a interação. Na tabela abaixo, estão relacionadas as ferramentas metodológicas utilizadas durante as aulas observadas:

\begin{tabular}{|c|c|c|c|c|}
\hline \multicolumn{5}{|c|}{ Quadro representativo das ferramentas metodológicas utilizadas por Stephany } \\
\hline Aula & Data & Turma & Turno & Ferramentas metodológicas \\
\hline 1 & $27 / 05 / 2013$ & $4^{\circ} \mathrm{A}$ & Matutino & $\begin{array}{l}\text { Caça-palavras, gravuras para fixar } 0 \\
\text { vocabulário. }\end{array}$ \\
\hline 2 & $27 / 05 / 2013$ & $4^{\circ} \mathrm{B}$ & Matutino & Gravuras, mímicas e gestos. \\
\hline 3 & $27 / 05 / 2013$ & $3^{\circ} \mathrm{A}$ & Matutino & Música e jogos. \\
\hline 4 & $27 / 05 / 2013$ & $1^{\circ} \mathrm{A}$ & Vespertino & Música e desenho. \\
\hline 5 & $27 / 05 / 2013$ & $1^{\circ} \mathrm{B}$ & Vespertino & Música, desenho e objetos. \\
\hline 6 & $27 / 05 / 2013$ & $3^{\circ} \mathrm{B}$ & Vespertino & $\begin{array}{l}\text { Ensaio da quadrilha: atividade impressa com } \\
\text { desenho. }\end{array}$ \\
\hline 7 & $29 / 05 / 2013$ & $2^{\circ} \mathrm{A}$ & Vespertino & $\begin{array}{l}\text { Jogos, música, gestos, desenhos, convite de } \\
\text { aniversário e simulação de história em }\end{array}$ \\
\hline
\end{tabular}




\begin{tabular}{|c|c|c|c|l|}
\hline & & & & quadrinho com desenho. \\
\hline 8 & $29 / 05 / 2013$ & $2^{\circ} \mathrm{B}$ & Vespertino & $\begin{array}{l}\text { Música, jogos, convite de aniversário e } \\
\text { simulação de histórica em quadrinho com } \\
\text { desenho. }\end{array}$ \\
\hline 9 & $14 / 08 / 2013$ & $2^{\circ} \mathrm{A}$ & Vespertino & Música e desenhos. \\
\hline 10 & $14 / 08 / 2013$ & $2^{\circ} \mathrm{B}$ & Vespertino & Música, jogos e desenhos. \\
\hline 11 & $02 / 09 / 2013$ & $1^{\circ} \mathrm{A}$ & Vespertino & Crosswords, música, jogos e desenhos. \\
\hline 12 & $02 / 09 / 2013$ & $1^{\circ} \mathrm{B}$ & Vespertino & Música e desenhos. \\
\hline 13 & $05 / 09 / 2013$ & $2^{\circ} \mathrm{A}$ & Vespertino & $\begin{array}{l}\text { Música com personificação (uso de máscaras), } \\
\text { jogos e desenho. }\end{array}$ \\
\hline 14 & $05 / 09 / 2013$ & $2^{\circ} \mathrm{B}$ & Vespertino & $\begin{array}{l}\text { Jogos, música com personificação (uso de } \\
\text { máscaras) e desenho. }\end{array}$ \\
\hline
\end{tabular}

Quadro 2: metodologias utilizadas pela participante durante as aulas observadas

Nas aulas observadas, é notável a variação de ferramentas metodológicas (doravante FMs) utilizadas por Stephany. Contudo, a música é uma das que mais se destaca, uma vez que auxilia na memorização de vocábulos, pois, conforme Pereira (2007), a aquisição do vocabulário é considerada prioridade para a maioria dos aprendizes, além de contribuir para a desenvoltura oral e proporcionar diversão aos alunos. Ainda conforme a autora, o professor deve centrar o processo de ensinoaprendizagem no aluno levando em consideração o mundo do aprendiz, e seu primeiro passo é proporcionar a aproximação entre contexto social e contexto escolar para que o aprendiz se envolva na aprendizagem, e a música é um dos caminhos pelo qual se pode realizar tal interação. A música, de acordo com Murphey (1990, 1992 apud PEREIRA 2007), trabalha com a memória de longo prazo ${ }^{5}$ corroborada pelo fenômeno "a canção ficou na minha cabeça", que acontece devido ao processo de repetição, por meio do qual se consolida a aprendizagem e torna a memorização mais fácil e prazerosa, aliando, assim, a aprendizagem ao prazer. Ainda segundo a autora, diversos temas são abordados na música, os quais englobam variados campos semânticos, possibilitando a aquisição de vocabulários.

De acordo com Pereira (op. cit.), vários autores abordam a utilização da música como recurso didático lúdico e abrangente, tais como Richards (1969), Murphey (1990,

\footnotetext{
5 A memória de longo prazo, ou memória referencial, é a responsável pelo processo de formação e consolidação de arquivos mentais, ou seja, pelo armazenamento duradouro de informações. A duração desse armazenamento pode variar de horas meses e décadas, tais como as lembranças da infância ou conhecimentos adquiridos na escola. (Informações adquiridas no site Dr. Drauzio Varella, disponível em $<$ http://drauziovarella.com.br/corpo-humano/memoria/> acessada em 17 set. 2014)
} 
1992), Lima (2004), Pereira (2004), Meller (2006), Pessôa e Duqueviz (2006), dentre outros. Para estes, ainda segundo a autora, pode-se utilizar a música "para trabalhar as habilidades da língua e os componentes do sistema linguístico, bem como para promover interação e motivação", além de proporcionar uma aprendizagem mais prazerosa e descontraída, levando em consideração que, na maioria das vezes, as aulas de LE são mais expositivas.

Em conformidade com Pereira (2007), as aulas expositivas podem acarretar processos de stress, impedindo e atrapalhando a aprendizagem. Ainda segundo a autora, outros autores (MURPHEY, 1990,1992; ALBUQUERQUE E SANTOS, 2002) afirmam que é possível utilizar a música para aplacar este stress, por proporcionar uma aprendizagem descontraída e, consequentemente, mais positiva, uma vez que a música está presente na vida de todo ser humano - canções natalinas, de rádio, mantras, etc. -, tanto que o "ritmo é uma força vital subjacente ao mundo" (BIRKENSHAW, 1994 apud PEREIRA, op. cit., p. 32).

Contudo, para a autora, a música pode ser utilizada para o ensino e a aprendizagem de tópicos gramaticais, de itens lexicais, de padrões sintáticos, de pronúncia, entonação, tonicidade e ritmo; para a memorização e automação; para a prática de habilidades de produção e compreensão oral e escrita; e para o reconhecimento e a discussão de aspectos socioculturais.

Outra variável que orienta a abordagem de Stephany são as crenças. Para Barcelos (2006), as crenças são vistas como

[u]ma forma de pensamento, como construções da realidade, maneiras de ver e perceber o mundo e seus fenômenos, co-construídas em nossas experiências e resultantes de um processo interativo de interpretação e (re) significação. Como tal, crenças são sociais (mas também individuais), dinâmicas, contextuais e paradoxais (BARCELOS, 2006, p. 18).

A maneira como o educador utilizará a música dependerá das crenças que o envolvem, especificamente, a visão que possui sobre o processo de ensinoaprendizagem. Durante a entrevista realizada com Stephany, ao questioná-la a respeito do papel da música em suas aulas, pôde-se observar a crença afetiva que envolve esta FM:

Eu acho que a música é muito legal porque me aproxima dos alunos [contente.] Acho mais para a afetividade. E também, porque com a música tem a questão da memorização. Eu ensino a música num dia, a gente canta a música 50min/1 hr e na próxima aula eu nem preciso colocar o CD porque eles já sabem a música 'de cor'. [...]. Eu acho mais para a animação, e para que eles desenvolvam o gosto mesmo 
pela lingua inglesa. E na música é que eu percebo que eles conseguem usar as estruturas, e eles sabem o que significam. Então eu acho que é esse o papel.

[Trecho da entrevista]

Para Stephany, a música corrobora na aproximação aluno/professor, na memorização e na aceitação da aprendizagem de uma nova língua que, segundo Lile (2002 apud PEREIRA, 2007), também proporciona a motivação, que é um elemento fundamental para a aprendizagem. Entretanto, em apresentações festivas (dia dos pais, dia das mães, etc.), Stephany não compartilha a ideia de apresentar músicas, pelo fato de não trazer uma fundamentação, um conteúdo para a aprendizagem:

[...] O que me irrita um pouco são essas comemoraçõezinhas sabe? [...] eu tive que parar de dar aulas sabe? Tempo perdido, porque já tem pouquíssimas aulas de inglês, ai eu tenho que ficar um mês, muitas vezes mais que um mês [...], mas então, eu acho que isso pode ser trabalhado de outras formas dentro da aula de inglês. Não tem que parar de dar aula de inglês ir lá e ensinar eles a dançar. Não. Eu acho que a cultura pode ser trabalhada de outra forma [...]. Podemos trabalhar dia dos pais, só que não precisa aprender uma música para cantar para os pais e ter que ensaiar várias horas, vários dias, vários meses para aprender a cantar aquela música e parar com o conteúdo. Não. [...] Horas que poderiam ser melhor aproveitadas com outros assuntos, inclusive para trabalhar temas criticos. [...], mas eu também entendo essa necessidade disso, apesar de não gostar, é cultura né.

[Trecho da entrevista]

Ou seja, a música, para Stephany, possui um papel pedagógico para a aprendizagem da LI, pois, conforme lembra Barcelos (1999), tanto os professores quanto os alunos possuem hábitos, costumes e expectativas em relação à aquisição da LI na sociedade, os quais são interiorizados coletivamente, tornando-se uma ressignificação individual de acordo com a cultura específica de cada qual, possibilitando, assim, a compreensão da relação aprendizagem/cultura. Portanto, nas aulas observadas, pôde-se notar que as músicas se referiam aos conteúdos exigidos no plano anual do munícipio; e as experiências anteriores de Stephany, em relação à música, revelaram-se proveitosas, tornando seu uso habitual nas aulas da professora.

[...] a professora canta e dança junto com os alunos a música 'cabeça, ombro, joelho e pé' na língua inglesa. Todos cantam. Após a música revisa as partes do corpo humano fazendo gestos e apontando-as.

[Trecho da nota de campo sobre a Aula 3]

[...] ela pediu para os alunos pegarem os cadernos para copiar uma música nova: Song: 'The hot $\operatorname{dog}^{\prime 6}[\ldots]$ cantam a música e em seguida ela os ensina a fazer uma "Comics" utilizando as personagens da música e o que eles dizem.

[Trecho da nota de campo sobre a Aula 7]

\footnotetext{
${ }^{6}$ 'The hot dog': 'O cachorro-quente' - a música narra a história de crianças que avistam um vendedor de cachorro-quente e pedem para que ele o sirva com ketchup e mostarda.
} 
Conforme supracitado na Aula 3, o conteúdo em questão eram as partes do corpo humano. Os alunos cantaram e memorizaram as partes do corpo humano, pois durante a música o aluno deveria tocar a parte do corpo a qual estava sendo dita. Salienta-se o entusiasmo e a afinidade das crianças com a LI, que, segundo Tame (1984 apud Graciano op. cit., p. 33), "[é] difícil encontrar uma única fração do corpo que não sofra a influência dos tons musicais", ou seja, a música é capaz de envolver tanto o sistema psíquico, quanto o físico dos aprendizes, além de reduzir a ansiedade e construir um ambiente agradável, favorável à aprendizagem.

Além desse aspecto agradável do uso da música, na Aula 7 evidenciou-se que Stephany, ao introduzir a música que fazia referência ao conteúdo trabalhado anteriormente - comidas de festas de aniversário - aproveita para questionar o fato de que nem todas as pessoas fazem festas que conteriam todos os tipos de comida e que cada um poderia dar uma festa conforme sua situação financeira, abordando o tema, aparentemente trivial, de maneira crítica, problematizando as diferenças sociais, já que para ela, o ensino crítico (PESSOA \& BORELLI, 2011) é possível, mas deve ser ministrado cuidadosamente:

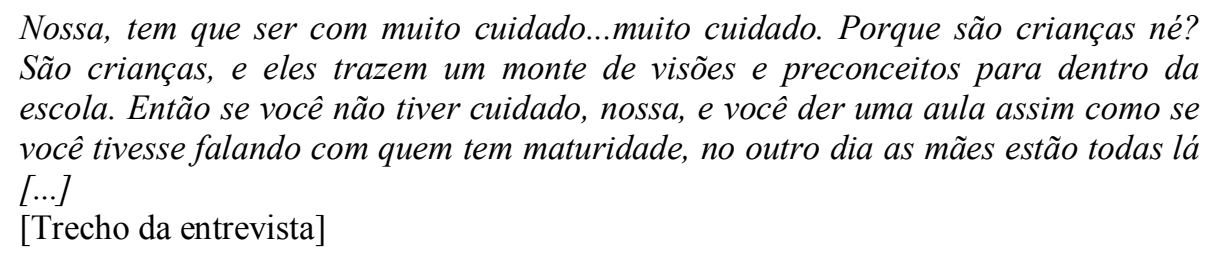

Assim, para Stephany, o trabalho com temas críticos requer muito cuidado devido à imaturidade intelectual dos alunos e as visões formadas que trazem do meio familiar no qual vivem, o que pode acarretar conflitos, os quais poderão ser irreversíveis tanto para o educador quanto para o educando.

Os jogos são outro tipo de FMs utilizadas por Stephany. Durante as aulas observadas, o jogo, além de contribuir, como a música, para a fixação de vocábulos, é uma forma de raciocinar com mais agilidade, pois quando se é feita a pergunta, o aluno que a responder com mais rapidez é o vencedor. É uma das técnicas utilizadas por Stephany como método para acalmar uma turma agitada. Por exemplo, na Aula 14, Stephany inicia a aula com o jogo sit down and stand $u p^{7}$ com o intuito de acalmar a turma e, ao premiar o vencedor, aproveita a oportunidade e faz uma revisão das cores na

\footnotetext{
${ }^{7}$ Jogo equivalente ao "Vivo e morto" na cultura brasileira.
} 
LI, já que, de acordo com Rocha (2012), o entrecruzamento entre as atividades é importante por permitir que os alunos "atuem a partir de seus pontos fortes e interesses centrais", possibilitando outras formas de aprendizagem.

Outra FM são os desenhos, os quais Stephany utiliza para introduzir, seja um conteúdo, seja uma música. Com a utilização destes e de gravuras não são necessárias as traduções. Assim, os alunos associam o vocábulo à imagem. Porém, ao introduzir um conteúdo novo, seja por música ou desenho, Stephany contextualiza a situação criando uma história que, segundo Tonelli (2013), se classifica na categoria de histórias reais por relatar fatos os quais podem não acontecer, "mas que são possíveis de acontecerem no cotidiano de cada um" (TONELLI, 2013, p. 301), presentes em uma relação entre amigos/colegas, nas brincadeiras e até mesmo nas possíveis aventuras a serem vividas pelas crianças.

A formação reflexiva promove a ressignificação do papel do educador quando este passa a questionar sua função técnica de aplicador de teoria (Pessoa e Borelli, op. cit.), pois refletir criticamente denota a busca da compreensão dos fatores que abrangem os acontecimentos da sala de aula e dos que interferem na educação e intervêm nas práticas dos participantes pesquisados, sejam eles professores, alunos, dentre outros.

O educador, quando reflexivo, reflete sobre seu papel e sua prática a partir da elaboração do plano de aula (PA), que Stephany define como

a organização de meu trabalho. É a reflexão sobre as necessidades de meus/minhas alunos/as, os materiais de ensino e aprendizagem, currículos impostos, meus objetivos/expectativas, minhas metodologias e formas de avaliação.

[Questionário]

Contudo, pode-se dizer que Stephany possui uma formação reflexiva por refletir criticamente sobre suas ações, além de pensar "em maneiras de viabilizar o sucesso do ensino e da aprendizagem" no momento em que planeja suas aulas, reconstruindo ou adaptando materiais, metodologias ou avaliação.

No trecho supracitado, Stephany usa o pronome meu, pois para ela não existe um planejamento único para todos os professores, o que a levou a dar a seguinte resposta ao proporem que formulasse o planejamento anual municipal:

Fazer uma apostila para os professores, e eu falei que não, que isso é muito arriscado porque cada contexto é único... cada professor é único. Como eu posso decidir qual é o melhor conteúdo, qual a melhor forma de trabalhá-lo, sendo que meu contexto é um, eu sou uma, meus alunos são únicos. Como é que eu posso decidir isso para outro professor, para outros alunos, para outro contexto? [...] [Entrevista] 
Para Stephany, não existe uma homogeneidade de profissionais, de alunos ou de contextos sociais. Cada indivíduo possui sua unicidade, além de compreender seu papel de transformadora que, conforme Pessoa e Borelli (2011), é o pressuposto na atitude crítica, porque o educador

[p]recisa compreender seu papel na sociedade e sua responsabilidade de agente transformador, bem como procurar conscientizar-se das forças externas que intervêm na educação. Dentre tais forças está a instituição escolar que, com seus princípios e valores, serve a interesses políticos diversos e pode manter ou transformar a realidade social. Dentro desse contexto estão nossas ações, cabendo a nós, então, questionar os interesses que tem orientado nossa prática, a relevância do que ensinamos aos nossos alunos e a maneira como temos desempenhado nosso papel social (PESSOA; BORELLI, 2011, p.25).

Em virtude de um ensino transformador, o educador deve se questionar e refletir sobre suas ações para que desempenhe seu papel social. Tanto que, para Contreras (2002), é necessário resgatar a racionalidade reflexiva do educador, objetivando compreender a verdadeira forma nas quais se abordam as situações problemáticas da prática.

Conforme Contreras (2002, p. 109), a prática constitui-se "um processo que se abre não só para a resolução de problemas de acordo com determinados fins, mas à reflexão sobre quais devem ser os fins", ou seja, é necessário que o educador reflita sobre sua prática e qual a contribuição desta para seus educandos, uma vez que, ainda segundo o autor, a análise e a crítica da própria prática permitem melhorias no desempenho dos professores e na capacidade de criar situações regidas para valores e critérios educativos. Por conseguinte, os demais elementos - série/turma/alunos, experiência na área de ensino de LI, preferências, inserção de música/filme/vídeo, interdisciplinaridade, temas, oralidade, diversão, brincadeiras e jogos e elementos culturais - são relevantes para Stephany durante o planejamento das aulas, visto que ela leva em consideração a motivação, a afetividade, a colaboração e a diversão, para que os alunos dos anos iniciais possam aprender a LI.

O professor, ele não é o responsável nem tem que ser por tudo, porque a aprendizagem, o ensino não depende só do professor, depende do aluno, da coordenação, da direção, de todo mundo, da colaboração entre todo mundo junto. O professor não é o responsável nunca por tudo. É um dos, mas sem o aluno não tem professor... né? E o próprio aluno, o próprio colega pode ser professor do outro colega também. Então a responsabilidade não é só de um.

[Entrevista] 
Portanto, Stephany reflete que, para melhor aproveitamento do ensino de LI é necessária a colaboração de todos do contexto escolar, sejam alunos, professores, gestão administrativa, entre outros. Porém, a teoria também é um elemento fundamental no desempenho do professor, pois, segundo Pimenta (2005, p. 24), "o saber docente não é formando apenas de prática, sendo também nutrido pelas teorias da educação", por dotar o educador de variados pontos de vista para uma ação contextualizada, oferecendo perspectivas para análises, as quais favorecem a compreensão dos contextos, sejam eles, sociais, culturais, históricos, organizacionais e de si mesmos como profissionais, nos quais se dá a atividade docente, intervindo e transformando-os.

\begin{abstract}
$E^{8}$ : Você acha que, para o professor de inglês dos anos iniciais, faz mais falta saber a Língua Inglesa ou faz mais falta ser pedagogo?

$P^{9}$ : "Mas eu acho assim que tudo o que o professor faz na escola, independente do professor é.. Tem só magistério, independente do que, do que ele estudou, a experiência conta muito, e tudo que ele faz ali dentro é teoria, não é? A gente tem que encarar a teoria como uma reflexão sobre a prática. E todo professor que trabalha, ele reflete sobre o que ele faz. Então, teoria não é só o que sai daqui e vai funcionar lá, tem que ser praticado. Não. Eu acho que não. Que a prática é uma teoria, e que ela tem quer ser trazida pela universidade e não o contrário [...]”." [Entrevista]
\end{abstract}

Para Stephany a teoria não compreende apenas os conteúdos apresentados pela universidade. A prática se torna uma teoria quando o professor reflete sobre sua ação, uma vez que este, segundo Pimenta (2005, p. 43), "pode produzir o conhecimento a partir da prática, desde que na investigação reflita intencionalmente sobre ela, problematizando os resultados obtidos com suporte da teoria", nominando-o pesquisador de sua própria prática. De acordo com Lisita (2011, p. 31), a racionalidade reflexiva permite a construção de diálogos entre "as teorias e os objetivos da formação e as teorias enraizadas nas práticas dos professores".

Conforme aponta Silvestre (2011), os professores de LE devem ir além da reflexão sobre a prática, ou seja, devem explorar os limites da sala de aula e lançar um olhar crítico sobre a escola, por acreditar que o papel do educador consiste em provocar mudanças, insistindo na busca por momentos críticos.

Pessoa e Urzêda-Freitas (2012, p. 57) lembram que o objetivo do ensino crítico de línguas é preparar o discente para utilizar a língua em situações reais, isto é, "grande importância é dada às atividades significativas que simulam as condições autênticas de

\footnotetext{
8 "E" faz referência à entrevistadora.

9 "P" faz referência à participante desta pesquisa.
} 
interação e comunicação das quais o aprendiz pode participar”, e, nessa perspectiva, ainda conforme os autores, a escola torna-se um ensaio para a vida, por desempenhar um papel fundamental na formação de identidades, o que vai ao encontro da afirmação de Sarup (1996 apud Pessoa e Urzêda-Freitas, op. cit. p. 57), na qual as escolas “determinam em grande parte não somente o que as pessoas fazem como também quem são, serão e podem vir a ser".

Em conformidade com Freire (1982), os autores entendem que o conhecimento é construído a partir do processo colaborativo entre discentes e docentes, para que a escola se transforme em um espaço que propicia questionamentos, com o intuito de transformar a realidade, levando os alunos a perceberem o mundo como ele é, com seus problemas e desigualdades, propondo soluções e contestações de ideias as quais, geralmente, são apresentadas como discursos únicos, uma vez que, como professores, é necessário fazer com que os alunos percebam a capacidade que possuem para agir e modificar as injustiças sociais.

Em conformidade com Pessoa e Urzêda-Freitas (2012), para o ensino ser crítico é necessária a problematização não apenas pelo professor, mas também por atividades que desafiem os aprendizes a pensar em como agir de forma diferente, vislumbrando possibilidades de mudanças, tanto que Rocha (2012) corrobora com a ideia de que o ensino de LI deve preparar o aprendiz para realizar uma leitura crítica do mundo em suas diferentes formas e linguagem.

Rocha (op. cit.) considera o ensino crítico relevante para o ensino de LI nos anos iniciais do EFI mediante o caráter heterogêneo de culturas, de práticas sociais, de conhecimento, etc., assim, defende o papel da escola de criar e promover ações que permitam a miscigenação de culturas e de letramentos de naturezas variadas. Dada à perspectiva do ensino crítico, faz-se necessária a problematização por meio da oralidade e de atividades (PESSOA; URZÊDA-FREITAS, 2012) capazes de provocar a desestabilidade do aluno (ROCHA, 2012), portanto, na citação abaixo, retratamos as reflexões de Stephany relacionadas à utilização de temas críticos.

E: Você tocou no ponto do ensino crítico. Com os anos iniciais, você acha que tem condição de problematizar algum tema, alguma coisa...

P: Nossa, tem que ser com muito cuidado. [...]. Porque são crianças né? São crianças, e eles trazem um monte de visões e preconceitos para dentro da escola. Então se você não tiver cuidado, nossa, e você der uma aula assim como se você tivesse falando com quem tem maturidade, no outro dia as mães estão todas lá. Isso nunca me aconteceu, mas aconteceria se eu não soubesse o que eu estou fazendo. Ai, por exemplo, eu trabalho família, 'mother, father, brother, sister' no primeiro 
ano... a família nuclear. Só que depois que eu mostro aquela família nuclear, eu falo com eles que existem outros tipos de família também. Existem famílias só de mães, só de pais, de mãe solteira, de pai solteiro.... Então existem famílias de todos os jeitos, de homem com homem, de mulher com mulher. E quando eu começo a falar disto, eu já começo a ver a reação deles. Eles se assuntam, eles se recusam a ouvir aquilo. Crianças. Então por isso tem que ter cuidado. Então eu não toco muito nessa tecla, mas eu falo que estas famílias existem. E teve uma época que eu também trabalhei família, eu acho que foi $3^{\circ}$ ano, que eu mostrei algumas famílias diferentes e levei fotos. E eles não gostaram de ver as fotos... das familias diferentes sabe? Mas isso é normal, é normal. Eu não esperava que eles fossem receptivos a ver esses outros tipos de família. Normal. Eu acho o que é normal para eles, a família que eles aceitam é do pai, da mãe e dos filhos, quando muito, da mãe solteira e dos filhos. Isto, porque é dificil achar o pai solteiro. Mas eu tento, só que é assim... um trabalho de formiguinha sabe? De formiguinha. [...] Igual quando eu fui falar sobre profissões mesmo. Eu levei um monte de figurinhas das profissões, da médica, da professora. E dai eu pedi para escolherem as profissões, as melhores profissões. Ai eles escolheram médico, são as melhores. Eu vi lá que eles deixaram professor nas piores, faxineiro. Está vendo o preconceito? E dai eu tentei problematizar com o $5^{\circ}$ ano: 'Por que a profissão de professor é ruim?' 'Por que a profissão do faxineiro é ruim?' Entende? 'Por que a do médico é a boa?' 'E a do cantor é a boa?' 'E a da atriz é a boa?'. Eles: 'Uai teacher, porque dá muito dinheiro'. Eu falei: 'Mas não é só o dinheiro que a gente tem que olhar, né? '. E o que eu percebi também assim... é que nas fotos as pessoas negras mesmo tendo uma boa profissão, eles colocaram na profissão ruim, entende? Tinha lá um enfermeiro negro, eles colocaram na profissão ruim. [...] eu falei: 'Por que a do enfermeiro tá aqui nas desprivilegiadas, das desprestigiadas?'. 'Uai, não sei teacher'. 'Não é porque ele é negro não? '. Então sabe, eu vou dando algumas injeçõezinhas".

[Entrevista]

Depois de treinar o vocabulário a professora aproveita para conscientizar os alunos sobre a importância de cuidar da natureza.

[Diário de observação - AULA 12]

Durante a entrevista e as observações realizadas, foi possível observar que Stephany não só acredita na possibilidade de se trabalhar o ensino crítico com os anos iniciais do EFI como o faz, desde que tenha cuidado devido à imaturidade intelectual dos alunos e também outros fatores - estereótipos, crenças, etc.

Portanto, apesar das problemáticas e desigualdades (ROCHA, 2012) que regem o ensino de LI nos anos iniciais do EFI, é possível trabalhar a criticidade dos alunos, já que oferece uma abertura para que os aprendizes exponham seus conhecimentos, pois é pela comunicação que eles definem e constroem a realidade social, seja do contexto escolar, do familiar e do mundo, além de delinearem suas subjetividades (PESSOA; URZÊDA-FREITAS, 2011).

A seguir, retomamos as perguntas da pesquisa e tecemos algumas considerações a respeito da investigação, e suas contribuições para a área da Linguística Aplicada e formação de professores. 


\section{CONSIDERAÇÕES FINAIS}

Respondendo à primeira pergunta do estudo - de quais ferramentas metodológicas a professora lança mão para facilitar a aprendizagem de língua inglesa para as crianças? - Consideramos que a participante corrobora com Tonelli (2013) ao promover uma ação de aprendizagem voltada para a interação com o uso de ferramentas metodológicas diversificadas. Conforme o quadro 2, apresentado no segundo capítulo, Stephany utiliza uma gama de FMs como músicas, caça-palavras, jogos, desenho e outros, os quais envolvem gêneros orais presentes no dia-a-dia da criança (ROCHA, 2012), além de promover a articulação e o cruzamento entre eles, por se relacionarem com determinado conteúdo que a professora quer apresentar aos seus alunos. Para ela, tais atividades proporcionam a motivação durante a aprendizagem e a apreciação da LI, pelo fato de o ensino de LI no EFI público estar envolto em um conjunto de preconceitos, pessimismos e desigualdades (ROCHA, op. cit.). Além de propiciar um ambiente convidativo para a aprendizagem, ou seja, um ambiente com vida, colorido, com cartazes e gravuras, que na maioria das vezes são criados pelos alunos, espalhados pelas paredes, acabam se tornando suportes para a realização de outras atividades, tais como os jogos.

A música é a ferramenta mais utilizada por Stephany, uma vez que contribui para a memorização de vocabulário, para a desenvoltura oral e para a diversão (PEREIRA, 2007). A participante acredita que, além da memorização, a música contribui para a aproximação entre aluno/professor e para a aceitação da aprendizagem de LI, proporcionando a motivação, que é um elemento fundamental durante o processo de aprendizagem. Entretanto, para Stephany, utilizar a música como uma ferramenta indispensável apenas ocorre a partir do momento que esta traga uma fundamentação, um conteúdo e não seja dada de forma aleatória, sem um objetivo específico.

Mediante as crenças apresentadas, respondemos a segunda pergunta - quais são as percepções e reflexões da professora sobre o ensino de LI nos anos iniciais? o que a professora diz sobre sua prática? - afirmando que Stephany é uma professora reflexiva, por refletir sobre sua prática, e esta, segundo ela, é, em si, uma teoria. Primeiramente, para conduzir sua ação na sala de aula, a participante parte do pressuposto que os alunos, em razão de estudarem em uma escola pública, possuem a crença de que não é possível aprender a LI. Portanto, ela reflete que o tempo destinado ao ensino de LI na 
rede pública é muito pouco, e cabe ao professor encontrar a melhor maneira de conduzir sua ação, tendo em vista a heterogeneidade de contextos, de professores e alunos.

Durante sua formação, Stephany não imaginava que um dia poderia ensinar LIC e quando foi aprovada no concurso se deparou com uma realidade a qual não conhecia, o que a fez refletir sobre a formação do professor, de modo que este tenha contato com vários tipos de público, uma vez que, para ela, trabalhar com crianças requer disposição e cabe ao professor o papel de agente transformador (ROCHA, 2012). Stephany acredita na aprendizagem com base no ensino crítico de LIC, desde que se tenha muito cuidado. Logo, para que o ensino de LI seja bem quisto, para Stephany, deve ocorrer o envolvimento entre todos os participantes (alunos, professores, gestão administrativa, etc.).

Conforme os resultados apresentados, o presente estudo contribui, primeiramente, para incrementar as pesquisas relacionadas à formação de identidade dos docentes, ao ensino crítico e à ressignificação da formação docente através da formação reflexiva.

Outra contribuição teórica é o fato de investigar as problemáticas que cercam a ação docente no ensino de LI no EFI, desde a formação até a prática. Embora associados a apenas uma participante, suas reflexões podem motivar outros professores a se identificar com Stephany e a sentir a necessidade de refletir sobre suas ações. Além, é claro, de oferecer a contribuição prática para o processo de formação de professores de LE, dado que apresenta as dificuldades enfrentadas pela participante ao se ver inserida em um contexto desconhecido. No entanto, é fundamental que se incluam, nos cursos de graduação de professores de LE, discussões - didáticas, metodológicas, de conteúdo e planejamento, etc. - acerca do ensino de LI no EFI.

Por conseguinte, em virtude dos resultados apresentados, considero que o ensino de LI no EFI não é apenas uma disciplina para preencher o tempo dos alunos, pois contribui para seu sucesso pessoal e intelectual, além de auxiliar na formação de identidade do indivíduo, tendo por base o ensino crítico. Assim, abre possibilidades para romper com a crença de que o ensino de LI na rede pública não é possível.

Como se pôde constatar, a ação docente requer reflexões, de modo que o professor se torne um pesquisador da própria ação, para que as mudanças possam se iniciar desde a sua formação acadêmica. Assim, é fundamental que a atenção seja voltada também ao aspecto prático da formação de professores, com a finalidade de oferecer subsídios que os capacitem na formação de cidadão críticos e reflexivos. 


\section{REFERÊNCIAS}

BARCELOS, Ana Maria Ferreira. A cultura de apender línguas (inglês) de alunos no curso de Letras. In: ALMEIDA FILHO, José Carlos P. de. O professor de língua estrangeira em formação. J. C. P. de Almeida filho (org.). Campinas, São Paulo: Pontes, 1999. p. 157-177.

- Cognição de professores e Alunos: tendências recentes na pesquisa de crenças sobre ensino e aprendizagem de línguas. In: BARCELOS, Ana Maria Ferreira. VIEIRA-ABRAHÃO, Maria Helena. Crenças e Ensino de Línguas: Foco no professor, no aluno e na formação de professores. Campinas, SP: Pontes Editores, 2006. p. 15-42.

. Explorando crenças sobre o ensino e aprendizagem de línguas em materiais didáticos. In: SCHEVERL, D.; SIQUEIRA, S. Materiais didáticos para o ensino na contemporaneidade: contestações e proposições / Denise Scheverl; Sílvio Siqueira (orgs.). Salvador, EDUFBA, 2012. p. 109-138.

BRASIL. Secretaria de Educação Fundamental. Parâmetros Curriculares Nacionais: Terceiro e Quarto Ciclos do Ensino Fundamental: Lingua Estrangeira. Brasília: MEC/SEF, 1998.

BROSSI, Giuliana Castro. Crenças e ações de uma professora de língua estrangeira (inglês) sobre o planejamento de curso e a aprendizagem: um estudo de caso. Dissertação de Mestrado - Universidade de Brasília. Brasília, 2008.

CONTRERAS, José. Autonomia de professores/ José Contreras, tradução: Sandra Trabuco Valenzuela; revisão técnica, apresentação e notas à edição brasileira: Selma Garrido Pimenta. São Paulo: Cortez, 2002.

ERICKSON, F. LINN, R. Quantitative and qualitative methods. New York: Macmillan, 1996.

JOHNSON, Donna M. Approaches to Research in Second Language Learning, Longman. New York, 1992.

LIMA, Flávio. Dicas de composição musical. Maceió, 2006. Disponível em: http://www.overmundo.com.br/overblog/dicas-de-composicao-musical-artigo-1-de-10. Acesso em: 08 set. 2014.

LIMA, Solange dos Santos. Crenças e expectativas de um professor e alunos de uma sala de quinta série e suas influências no processo de ensino e aprendizagem de inglês em escola pública. In: BARCELOS, Ana Maria Ferreira. VIEIRA-ABRAHÃO, Maria Helena. Crenças e Ensino de Línguas: Foco no professor, no aluno e na formação de professores. Campinas, SP: Pontes Editores, 2006. p. 147-160.

LISITA, Verbena Moreira Soares de Sousa. Contribuições da racionalidade reflexiva para a formação de professores. In PESSOA, Rosane Rocha. BORELLI, Julma Dalva 
Vilarinho Pereira. Reflexão e crítica na formação de professores de língua estrangeira. Goiânia: Editora UFG, 2011. p. 31-58.

LÜDKE, Menga. Pesquisa em Educação: Abordagens Qualitativas/Mega Lüdke, Marli E.D.A. André. São Paulo: Ed. Pedagógica e Universitária - EPU -, 1986.

MENEZES DE SOUZA, Lynn Mario Trindade. Professor de inglês e os letramentos no século XXI: métodos ou ética? In: JORDÃO, C. M.; MARTINEZ, J.Z.; HALU, R. C. Formação desformatada: práticas com professores de língua inglesa. Campinas, SP: Pontes Editores, 2011. p. 279-299.

NUNAN, David. Second Language Teaching and Learning. Heinle \& Heinle, Boston, 1999.

OLIVEIRA, Hélvio Frank. Esculpindo a profissão professor: experiências, emoções e cognições na construção das identidades docentes de licenciandos em letras. Trabalho de Conclusão de Curso (Pós-graduação) - Universidade Estadual de Goiás. Goiânia: 2013.

PEREIRA, Paula Graciano. Reflexões sobre o uso de música na sala de aula de LE: as crenças e a prática de dois professores de inglês. Trabalho de Conclusão de Curso (Pós-graduação) - Universidade Federal de Goiás, Goiânia, 2007.

PESSOA, Rosane Rocha. BORELLI, Julma Dalva Vilarinho Pereira. Reflexão e crítica na formação de professores de língua estrangeira. Goiânia: Editora UFG, 2011. p. 930 .

PESSOA, Rosane Rocha. URZÊDA FREITAS, Marco Túlio de. Ensino crítico de línguas estrangeiras. In: FIGUEIREDO, Francisco José Quaresma de. Formação de professores de línguas estrangeiras: princípios e práticas. Francisco José Quaresma de Figueiredo (org.). Goiânia: Editora UFG, 2012. p. 57-80.

PIMENTA, Selma Garrido. Professor reflexivo: construindo uma crítica. In: PIMENTA, S. G.; GHEDIN, E. Professor reflexivo no Brasil: gênese e crítica de um conceito / S. G. Pimenta, Evandro Ghedin (orgs). São Paulo: Cortez, 2005. p. 17-52.

ROCHA, Cláudia Hilsdorf. Reflexões e Propostas Sobre Língua Estrangeira no Ensino Fundamental I: Plurilinguismo, multiletramentos e transculturalidade. Campinas, São Paulo: Pontes Editores, 2012. Coleção: Educação \& Linguagem - vol. 1.

ROSA, Milton. OREY, Daniel Clark. O campo de pesquisa em etnomodelagem: as abordagens êmica, ética e dialética. Educ. Pesq. São Paulo, 2012, v.38, nº 4. p. 865879.

SEGANFREDO, Leandra Ines Santos. BENEDETTI, Ana Mariza. Professor de línguas estrangeiras para crianças: conhecimentos teórico-metodológicos desejados. Trabalho de Linguística Aplicada. Campinas, 2009. p. 333-335.

SILVESTRE, Viviane Pires Viana. Problematização da prática: momentos críticos de uma aula de inglês. In: PESSOA, Rosane Rocha. BORELLI, Julma Dalva Vilarinho 
Pereira. Reflexão e crítica na formação de professores de língua estrangeira. Goiânia: Editora UFG, 2011. p. 81-94.

TONELLI, Juliana Reichert Assunção. Histórias infantis e ensino de inglês para crianças: reflexões e contribuições. Revista de C. Humanas, Viçosa, v.13, n.2, p. 297315, julk./dez. 2013.

VIEIRA-ABRAHÃO, M. H. Crenças, pressupostos e conhecimentos de alunosprofessores de língua estrangeira e sua formação inicial. In: VIEIRA-ABRAHÃO, M. H. (Org.) Prática de ensino de Língua Estrangeira: experiências e reflexões. Campinas, Pontes, 2004.

\section{AS AUTORAS}

Jeovana Karla de Oliveira Dias graduou-se em Letras Português/Inglês em 2014. É pesquisadora voluntária no projeto de pesquisa "O planejamento de curso, as crenças e ações de professores de LI nos anos iniciais: educação ou sofrimento?" e autora de trabalho de conclusão de curso intitulado "Compondo A Profissão: Reflexões E Ações Que Norteiam A Prática De Uma Professora De Língua Inglesa Para Crianças”, relatando resultados da pesquisa.

E-mail:

Giuliana Castro Brossi é docente do curso de Letras Português/Inglês na UEG, professora de Estágio Supervisionado de Língua Inglesa I, e orientadora do trabalho de conclusão de curso.

E-mail: giulianabrossi70@gmail.com 